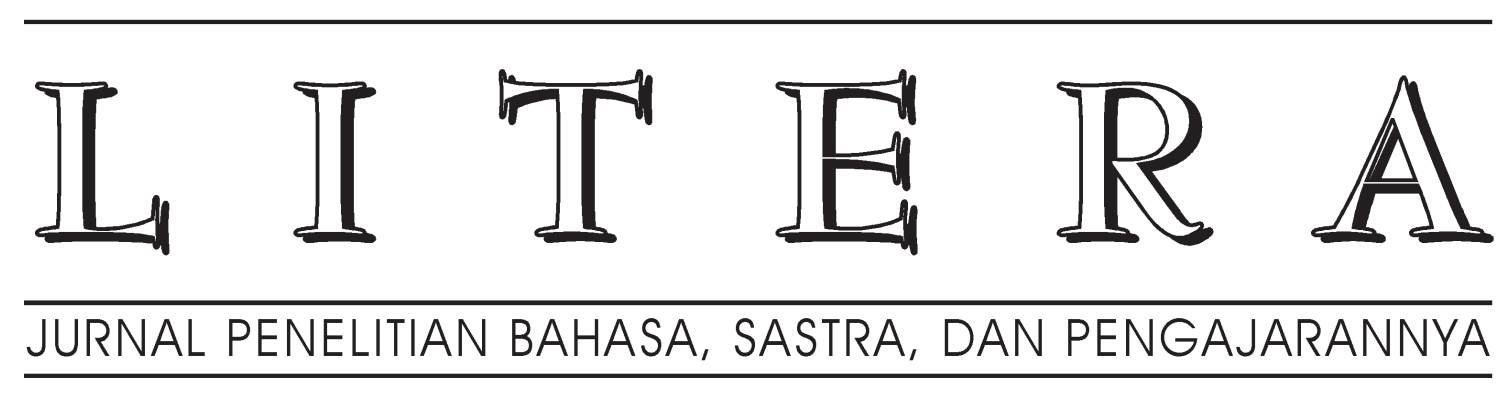

Berdasarkan SK Dirjen Dikti Nomor: 66b/DIKTI/Kep/2011, tanggal 9 September 2011 tentang Hasil Akreditasi Terbitan Berkala Ilmiah, LITERA dinyatakan sebagai Terbitan Berkala Ilmiah Terakreditasi, periode Agustus 2011 sampai dengan Agustus 2016 


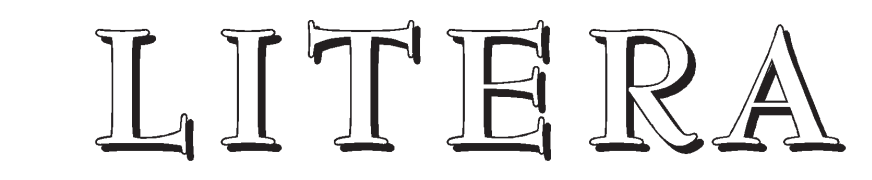

Jurnal Penelitian Bahasa, Sastra, dan Pengajarannya

Volume 12, Nomor 1, April 2013

* Alih Kode dalam Proses Pembelajaran Bahasa Inggris di SMA .... Margana 


\title{
ALIH KODE DALAM PROSES PEMBELAJARAN BAHASA INGGRIS DI SMA
}

\author{
Margana \\ FBS Universitas Negeri Yogyakarta \\ email: margna@yahoo.com
}

\begin{abstract}
Abstrak
Penelitian ini bertujuan mendeskripsikan alih kode dalam komunikasi di kelas yang dikaji dari sudut pandang sosiolinguistik. Subjek penelitian ini adalah 12 orang guru bahasa Inggris SMA di DIY. Data berupa tuturan alih kode dari bahasa Inggris ke dalam bahasa Indonesia atau sebaliknyadalam pembelajaran bahasa Inggris di kelas. Analisis data menggunakan metode deskriptif kualitatif. Hasil penelitian menunjukkan bahwa alih kode memiliki tiga fungsi, yakni (a) penyampaian materi, (b) pengelolaan kelas, dan (3) penanda wacana. Dengan merujuk pada fungsi tersebut penggunaan alih kode dalam pembelajaran bahasa Inggris dapat dilakukan selama dimaksudkan untuk memenuhi fungsi akademik. Sejalan dengan meningkatnya kemampuan berbahasa Inggris peserta didik, penggunaan alih kode perlu dikurangi.
\end{abstract}

Kata kunci: alihkode, proses pembelajaran, penandawacana

\section{CODE SWITCHING IN THE ENGLISH LEARNING PROCESS IN SENIOR HIGH SCHOOLS}

\begin{abstract}
This study aims to describe code switching in classroom communication from the sociolinguistic point of view. The research subjects comprised 12 English teachers in senior high schools in the Province of Yogyakarta Special Territory. The data were code switching utterances from English to Indonesian and vice versa in English language learning in the classroom. The data were analyzed using the qualitative descriptive method. The findings show that code switching has three functions, i.e. (a) material delivery, (b) classroom management, and (3) discourse markers. With reference to such functions, code switching in English language learning can be made as far as it satisfies academic functions. As the students' English mastery improves, the use of code switching needs to be reduced.
\end{abstract}

Keywords: code switching, learning process, discourse markers

\section{PENDAHULUAN}

Dalam masyarakat bilingual, termasuk masyarakat Indonesia pada umumnya dan masyarakat Yogyakarta khususnya, penggunaan dua bahasa atau lebih dalam peristiwa komunikasi merupakan fenomena yang biasa terjadi. Pendapat ini senada dengan pernyataan Wardhaugh (2010) yang menegaskan bahwa alih kode (AK) merupakan fenomena yang lazim terjadi di antara para dwibahasawan. Sebagai contoh di Yogyakarta, AK terjadi karena orang-orang yang terlibat dalam tindak komunikasi mengenal atau menguasai lebih dari satu bahasa, misalnya bahasa lokal (bahasa Jawa, Sunda, Madura, dan sebagainya), bahasa pertama (bahasa Indonesia), dan bahasa asing (Inggris, Arab, Jepang, dan sebagainya). Peristiwa pengalihan bahasa dari suatu bahasa ke bahasa lain tersebut oleh para pakar bahasa disebut alih kode atau code-switching (Romaine, 1995; MacSwan, 1999). 
Jika dilihat dari setingnya, peristiwa alih dapat terjadi baik dalam seting formal dan seting non-formal. Dalam seting formal, misalnya dalam kegiatan proses belajar mengajar di SMA di Yogyakarta, alih kode dari bahasa Inggris ke dalam bahasa Indonesia atau sebaliknya sering dilakukan oleh guru bahasa Inggris. Alih kode tersebut terjadi karena guru bahasa Inggris menggunakan lebih dari satu bahasa, yakni bahasa lokal, misalnya bahasa Jawa (bJ); bahasa Indonesia (bI); dan bahasa Inggris (bIng).

Terkait dengan penggunaan ketiga bahasa dalam pembelajaran bahasa Inggris di kelas tersebut, tulisan ini hanya mendeskripsikan peristiwa AK yang dilihat dari tinjauan fungsinya. Bentuk AK yang diteliti hanya berupa pengalihan dari bahasa Inggris (bIng) ke dalam bahasa Indonesia (bI) atau sebaliknya Pembatasan permasalahan penelitian ini dilakukan agar pembahasan peristiwa alih kode ranah instruksional dapat dilakukan secara lebih komprehensif, sistematis, dan terinci.

Istilah code-switching atau alih kode memiliki berbagai macam bentuk padanan yang digunakan dalam berbagai literatur dalam payung kajian bilingualisme, seperti language switching (peralihan bahasa), language insertion (penyisipan bahasa), language alternation (pertukaran bahasa), language mixing (percampuran bahasa), code-mixing (campur kode), codealternation (tukar kode), dan code changing (ganti kode). Kamwangamalu (1992) menggunakan istilah language alternation untuk code-switching dan code-mixing. Auer (1995) menggunakan istilah code alternation (pengalihan bahasa satu ke bahasa lain yang biasa terjadi dalam percakapan yang panjang) dan code insertion (penyisipan unsur kata dari suatu bahasa ke dalam konstruksi bahasa yang berbeda). Butler dan Gutierrez (2003) lebih suka menggunakan language mixing, yang diartikan sebagai kecenderungan dwibahasawan melakukan alih kode dari bahasa satu ke bahasa lain. Peristiwa percampuran bahasa ini mencakup code-switching, codemixing, and borrowing.

Merujuk uraian tersebut di atas, istilah code-switching (alih kode) dan code mixing (campur kode) banyak dijumpai dalam berbagai pustaka. Dengan kata lain, sebagian besar pakar bahasa lebih banyak menggunakan istilah code-switching dan codemixing dibandingkan dengan istilahistilah tersebut di atas. Menurut David (2003), code-mixing merupakan penggunaan dua bahasa secara bergantian tetapi hanya terbatas pada penggunaan token dari bahasa sasaran, sedangkan code-switching merujuk pada penggunaan lebih dari satu bahasa yang terjadi dalam komunikasi secara keseluruhan atau dalam satu ujaran. Berbeda dengan definisi yang disampaikan oleh David (2003), Poedjosoedarmo (1975:4) secara tegas membedakan antara alih kode dan campur kode. Alih kode adalah peralihan dari kode tertentu ke dalam kode lain yang memiliki fungsi yang jelas dalam peristiwa komunikasi. Sebaliknya, campur kode merupakan penyisipan kode yang berbentuk satuan lingual ke dalam struktur kalimat pada kode lain yang tidak memiliki kejelasan fungsi. Dengan kata lain, alih kode memiliki tujuan yang jelas dan didasari oleh motivasi-motivasi tertentu sedangkan campur kode tidak memiliki fungsi. Kekaburan tersebut disebabkan penutur tidak menguasai kedua bahasa yang diaktifkan terkait dengan aturan gramatika atau bentukbentuk leksikon dari dua bahasa yang diaktifkan tersebut.

Sehubungan dengan uraian di atas, tulisan ini menggunakan istilah AK yang diartikan sebagai pengalihan dari bahasa Inggris ke dalam bahasa Indonesia atau sebaliknya yang dilakukan oleh guru bahasa Inggris SMA dalam komunikasi di kelas. Pengalihan dari bIng ke dalam bahasa Jawa atau sebaliknya dan pengalihan bahasa Indonesia ke dalam bahasa 
Jawa tidak dianalisis. Selain itu, pengertian kode dalam hal ini hanya terbatas pada bentuk bahasa (bIng dan bI) yang dialihkan.

Peristiwa alih kode dalam seting kelas tidak dilakukan secara serampangan. Peristiwa AK tersebut memiliki fungsi yang jelas. Salah satu fungsi terjadinya alih kode adalah untuk memenuhi fungsi-fungsi komunikasi. Fantini (1985) menyebutkan bahwa alih kode dari suatu bahasa ke bahasa lain digunakan oleh penutur sebagai sarana metalinguistik yang memungkinkan seseorang mengaktifkan dua sistem kebahasaan yang berbeda. Goyvaerts dan Zembele (1992) menambahkan bahwa alih kode dapat dijadikan sebagai strategi negosiasi dalam tindak komunikasi. Cook $(1989,1991)$ mengatakan bahwa alih kode berperan sebagai strategi komunikasi yang dapat digunakan untuk pengendalian keberlanjutan tindak tutur. Sejalan dengan berbagai pendapat tersebut, David (2003) menambahkan bahwa alih kode dapat digunakan sebagai strategi komunikasi untuk mengatasi keterbatasan bahasa yang berakibat pada kemandegan berkomunikasi dan digunakan sebagai penanda anggota masyarakat tutur dan identitas penutur tertentu.

Pembahasan tentang fungsi AK juga disampaikan oleh Reyes (2004: 84) yang mengidentifikasi 11 fungsi AK dalam pembelajaran bahasa Inggris sebagai bahasa kedua di Spanyol. Pembagian fungsi AK tersebut merujuk pengelompokan fungsi AK yang disampaikan oleh Gumperz (1976), McClure (1981), dan Zentella (1997). Fungsi-fungsi AK tersebut adalah (1) representasi tutur (speech representation), (2) imitation quotation, (3) turn accommodation, (4) perubahan topik (topic shift), (5) perubahan situasi (situation switch), (6) penuntutan (insistence), (7) penekanan terhadap kata-kata tertentu (giving an emphasis), (8) pengklarifikasian (clarification or persuasion), (9) penun- jukkan kepada nama tertentu (person specification), (10) perubahan pertanyaan (question shift), dan (11) penanda wacana (discourse maker). Hal senada disampaikan oleh Ajmal (2010) yang mengemukakan 11 fungsi AK yang digunakan dalam kelas bilingual. Fungsi-fungsi tersebut adalah (1) pengklarifikasian maksud tertentu, (2) pemberian instruksi secara efektif, (3) pengalihan bahasa, (4) sosialisasi, (5) kompetensi bahasa, (6) penanda pergantian topik, (7) kemudahan dalam mengekspresikan pesan, (8) penekanan, (9) pengecekan pemahaman, (10) pengulangan, dan (11) menciptakan rasa kebersamaan.

Fungsi AK dalam komunikasi di kelas sebagaimana disampaikan oleh Reyes (2004) dan Ajmal (2010) memiliki kesamaan dan perbedaan. Kesamaan AK terjadi pada fungsi klarifikasi, penekanan, perubahan topik, pengulangan, Sementara itu, fungsi-fungsi lain seperti pemberian perintah, pengalihan, bahasa, sosialisasi, kompetensi bahasa, kemudahan dalam mengekspresikan pesan, pengecekan pemahaman, dan menciptakan rasa kebersamaan melengkapi fungsi AK yang disampaikan oleh Reyes (2004). Pembagian fungsi AK juga disampaikan oleh Jacobson dikutip oleh Faltis (1996: 34). Dia membedakan fungsi AK ke dalam empat topik, yakni (1) isi pembelajaran, (2) pengembangan bahasa, (3) keterikatan kurikulum, dan (4) hubungan interpersonal. Terkait dengan isi pembelajaran, Faltis (1996) membedakan fungsi AK menjadi empat fungsi, yaitu (a) pengembangan konsep, (b) mereviu pelajaran sebelumnya, (c) menarik perhatian peserta didik, dan (d) memberi pujian atau umpan balik terhadap pekerjaan atau partisipasi peserta didik. Dalam area pengembangan bahasa, fungsi AK diklasifikasikan menjadi tiga fungsi, yakni (a) peningkatan penguasaan bahasa target, (b) pemerkayaan kosakata, dan (c) pentransferan bahasa. Keterikatan kurikulum hanya terdiri dari 
satu fungsi, yaitu pergantian topik. Selanjutnya, hubungan interpersonal dibedakan menjadi dua fungsi, yakni (a) fungsi pemenuhan privasi atau formalitas, dan (b) kesesuaian pemilihan kode atau fungsi penghormatan.

Jika dicermati secara seksama, fungsi AK dalam pembelajaran bahasa Inggris di kelas dapat dibedakan menjadi dua, yakni (1) fungsi akademik, dan (2) fungsi nonakademik atau pemarkah wacana. Fungsi akademik dapat dipilah lagi menjadi dua, yakni (a) penyampaian materi atau berhubungan dengan isi materi pelajaran dan (b) pengelolaan kelas. Kedua fungsi tersebut digunakan untuk menganalis peristiwa AK yang dilakukan dalam komunikasi di kelas antara guru dan siswa SMA di Yogyakarta.

\section{METODE}

Penelitian deskriptif kualitatif ini menggunakan tiga tahapan strategis yang berurutan. Tahapan tersebut adalah (1) penyediaan data, (2) analisis data, dan (3) penyajian hasil analisis (Sudaryanto, 1993:5-7). Dalam kegiatan penyediaan data, teknik yang diaplikasikan dalam penelitian ini adalah teknik observasi yang disertai dengan teknik rekam. Pada tahap observasi, dicermati pemakaian segala bahasa yang digunakan dalam pembelajaran bahasa Inggris di kelas dan penggunaan AK yang dilakukan oleh guru bahasa Inggris SMA dalam komunikasi di kelas. Untuk membantu pelaksanaan observasi tersebut, diterapkan teknik rekam yang selanjutnya dilakukan transkripsi rekaman. Teknik simak yang diikuti dengan teknik catat juga digunakan dalam penelitian ini. Pada tahap ini dilakukan pencatatan bentuk-bentuk tuturan yang di dalamnya terdapat penggunaan bahasa dalam komunikasi di kelas dan tuturan yang ditengarahi terdapat pengalihan bahasa dari bIng ke dalam bI atau sebaliknya sebagai objek utama dalam penelitian ini. Pada tahap analisis data, metode yang digunakan dalam penelitian ini adalah metode deskriptif kualitatif. Selanjutnya, penyajian data menggunakan model informal, yakni model penyajian yang diwujudkan dengan menguraikan kaidah secara kebahasaan. Model penyajian informal dipaparkan langsung dalam setiap analisis.

Subjek penelitian ini adalah 12 guru bahasa Inggris SMA di Yogyakarta sebagai dwibahasawan atau multibahasa (bIng, bI, dan bJ) yang diasumsikan melakukan pengalihan bahasa Inggris ke bahasa Indonesia atau sebaliknya ketika mereka terlibat dalam pembelajaran bahasa Inggris di kelas. Nama-nama SMA tersebut adalah SMAN 1 Yogyakarta, SMAN 7 Yogyakarta, SMAN 1 Bantul, SMAN 2 Bantul, SMAN Tirto Nirmolo, SMAN 1 Kalasan, SMAN 2 Ngalik, SMAN 1 Mlati, dan SMAN 1 Prambanan.

Data penelitian ini berupa tuturan yang mengandung bentuk alih kode dari bahasa Inggris ke bahasa Indonesia atau sebaliknya yang dilakukan oleh guru bahasa Inggris SMA di DIY. Konteks data berupa dialog yang dilakukan oleh guru bahasa Inggris SMA ketika mereka melaksanakan pembelajaran bahasa Inggris di kelas. Data yang berwujud tuturan bIng dan bI yang diduga mengalami gejala AK tersebut dicatat beserta konteks yang mewadahinya dan dikodekan berdasarkan initial guru, jenis kelamin, urutan rekaman, kelas, bulan, dan tahun (S/P/1/ XI/APRIL/2009). Tindakan ini dimaksudkan untuk mengantisipasi kemungkinan adanya permasalahan yang memang tidak mungkin dilepaskan dari lingkup tuturan (Sudaryanto, 1993). Sumber data berupa catatan hasil observasi dan transkrip percakapan yang dilakukan oleh guru bahasa Inggris yang diperoleh melalui rekaman.

Mengingat kemungkinan banyaknya bentuk-bentuk alih kode dari bahasa Inggris ke bahasa Indonesia (ataupun ke bahasa lain) atau sebaliknya, penelitian 
ini hanya mengambil data yang memiliki bentuk alih kode dari bahasa Inggris ke bahasa Indonesia atau sebaliknya yang dilakukan oleh guru bahasa Inggris SMA di DIY dalam komunikasi di kelas.

\section{HASIL DAN PEMBAHASAN}

Berdasarkan analisis data, fungsi AK dalam komunikasi interaksional pada dasarnya dibedakan ke dalam dua kategori, yakni fungsi akademik dan fungsi non-akademik. Yang dimaksud dengan fungsi akademik adalah fungsi yang dimaksudkan untuk tujuan-tujuan pembelajaran atau akademik. Fungsi ini dibedakan menjadi dua kategori, yakni fungsi pembelajaran materi dan fungsi pengelolaan kelas. Fungsi non-akademik merujuk pada fungsi AK yang dimaksudkan bukan untuk tujuan akademik. Masing-masing temuan diperikan sebagai berikut.

\section{Fungsi Penyampaian Materi Pelajaran Bahasa Inggris}

Fungsi penyampaian materi ini mencakup (1) fungsi klarifikasi atau konfirmasi, (2) fungsi reiterasi, (3) fungsi eksplanasi, (4) fungsi ekplorasi, (5) fungsi elaborasi, (6) fungsi pengecekan pemahaman, (7) fungsi penekanan terhadap unsur-unsur kebahasaan tertentu, (8) fungsi membuat inferensi, (9) fungsi mengembangkan kosakata, (10) fungsi membahas tugas atau pekerjaan pesserta didik, (11) fungsi memberi feedback atau umpan balik, dan (12) fungsi melakukan refleksi. Masing-masing fungsi diperikan sebagai berikut.

Pertama, fungsi klarifikasi atau konfirmasi. Bentuk AK dari bIng ke dalam bI atau sebaliknya yang dilakukan oleh guru bahasa Inggris dalam pembelajaran bahasa Inggris di kelas dimaksudkan untuk mengklarifikasi atau mengkonfirmasi pertanyaan, jawaban, atau informasi disampaikan oleh peserta didik. Berikut disampaikan contoh data untuk fungsi klarifikasi sebagaimana ditunjukkan dalam tulisan cetak tebal.
(01) G : For this group, this group argument paragraph. And for the last, recommendation. You may elaborate of the main idea from the draft. Any question from you? Okay, paham belum maksudnya? Sini mengembangkan thesis. This is elaborate arguments. And then, elaborate recommendation.

(S/P/1/XI/APRIL/2009)

Kedua, fungsi reiterasi atau pengulangan. Dalam pembelajaran bahasa Inggris di kelas, guru bahasa Inggris melakukan AK dari bIng ke dalam bI atau sebaliknya untuk tujuan reiterasi atau pengulangan bentuk kata, frasa, atau klausa dalam suatu tuturan. Pengulangan tersebut dilakukan untuk memberikan penekanan pada unsur-unsur kebahasaan tertentu atau untuk mensejajarkan makna dua bentuk bahasa yang berbeda sehingga peserta didik cenderung memperoleh pemahaman yang lebih jelas. Contoh data untuk fungsi reiterasi disampaikan pada Data (02) .

(02) G : Hanung if Nana leave you what do you feel. Hanung will be sad if she leaves him. This is what we call factual or real conditional because it still has a chance to happen, masih sangat mungkin terjadi why because we talk about the future. This is the form of factual conditional. If you want to have more examples in your look at your book page 8. You can see the factual or real conditional.

(SL/P/1/XI/APRIL/2009)

Ketiga, fungsi eksplanasi. Peristiwa AK dari bahasa Ing ke dalam bI yang dilakukan digunakan untuk fungsi menjelaskan konsep atau makna bentukbentuk bahasa Inggris atau menjelaskan aturan gramatika bahasa Inggris. Dengan melakukan AK tersebut, peserta didik lebih memahami materi yang dibicarakan sehingga mereka dapat menggunakan- 
nya dalam memproduksi bentuk-bentuk bahasa Inggris. Berikut diuraikan contoh data untuk fungsi tersebut.

(03) G : Paragraph three, network include... Paragraph four, network formed six...ya ini seharusnya paragraph keempat. Network formed six itu paragraf keempat. Kemudian the village have.. itu paragraph kelima, yang berikutnya ecotourism dalam kurung itu paragraph keenam. itu paragraph ke 7. Harusnya untuk menjadi inti bacaan itu didukung lebih dari $50 \%$ paragraph. 7 bagi 2 berapa?

$\mathrm{S}$ : Famous

(E/L/1/XII/APRIL/2009)

Keempat, fungsi eksplotasi. Peristiwa AK dari bIng ke dalam bI yang dilakukan oleh guru bahasa Inggris dalam pembelajaran bahasa Inggris di kelas juga digunakan untuk fungsi mengeksplorasi pengetahuan sebelumnya yang terkait dengan topik materi pelajaran bahasa Inggris yang akan dipelajari. Fungsi eksplorasi AK ditunjukkan dalam tulisan cetak tebal pada data (04).

(04) G : Okay, last week I gave you homework. Have you done it? Sudah dikerjakan?

$\mathrm{S}:$ No.

G : No? Why? OK, we will discuss it maybe next week. And I have now a different text. What does surprise mean? What does surprise mean? Ya, surprise. What does surprise mean? Kejutan. Kejutan, ya. Surprising news? Nah, kalau surprising news?

S1: Berita mengejutkan.

$\mathrm{G}$ : Berita yang mengejutkan. We have surprising news this week. What is that? Baru-baru ini kan ada juga berita yang mengejutkan. What is that? Apa itu?

S2: Pesawat Hercules jatuh.

$\mathrm{G}$ : Pesawat Hercules yang jatuh. And how many victims are there?
S3: Ninety-eight. Sembilan puluh delapan.

(K/P/4/X/MEI/2009)

Kelima, fungsi elaborasi. Peristiwa AK dari bIng ke dalam bI dalam pembelajaran bahasa Inggris di kelas juga digunakan untuk fungsi mengelaborasi pemahaman terkait dengan topik materi pelajaran bahasa Inggris yang telah dimiliki oleh peserta didik. Berikut disampaikan contoh data untuk fungsi elaborasi.

(05) G : Ya this is the pattern. Ini yang kemarin kita bicarakan modelnya seperti itu that's the pattern. That what we call present conditional or present unreal conditional why because this is unreal. It may not happen tidak mungkin terjadi. Can you give me an example? if it was holiday, we would not go to school. Faktanya the fact is today is not holiday. So you come to school. Any other example? If I were a doctor I would helped the poor. So what is the fact? I am not a doctor I am a teacher. So you can make a conditional sentence like that. Jadi kamu kalau in Bahasa Indonesia, you can say berandaiandai is that right. You get the idea tahu maksudnya. Okay, the fact is that I am not a doctor. Jadi apa yang dikatakan dengan maknanya selalu berlawanan/kebalikannya is it right. If you want to have more example you can look at your look a head page 38. Evita can you read the information in the box

$S$ : (Evita membaca teks).

(SL/P/2/XI/APRIL/2009)

Keenam, fungsi mengulas materi yang sudah diajarkan. Peristiwa AK dari bahasa Ing ke dalam bI yang dilakukan oleh guru bahasa Inggris dalam pembelajaran bahasa Inggris di kelas digunakan untuk fungsi mereview apakah peserta didik 
masih ingat materi bahasa Inggris yang diajarkan. Lihat tulisan bercetak tebal pada Data (06) berikut ini.

(06) G: Okay, class. I'd like to remind you about the topic we discussed last week. What is it about? Apa yang telah kita pelajari pada pertemuan minggu lalu? Masih ingat?

S : Clause.

$\mathrm{G}$ : Clause. So, in Bahasa Indonesia, what is clause?

S : Klausa.

G: Klausa. Then, do you think that clause can stand by itself? Clause can stand by itself or it is only the part of the sentence? Which one do you think? The first or the second?

(C/P/3/X/APRIL/2009)

Ketujuh, fungsi penekanan terhadap unsur-unsur kebahasaan tertentu. Dalam pembelajaran bahasa Inggris di kelas, peserta didik menemukan istilah-istilah khusus atau istilah teknis dalam bahasa Inggris yang mereka belum mengetahui maknanya. Agar bentuk-bentuk tersebut tidak menggangu pemahaman peserta didik, guru bahasa Inggris melakukan AK dari bIng ke dalam bI atau sebaliknya untuk memberikan penekanan terhadap istilah-istilah khusus. Fungsi tersebut ditunjukkan dalam tulisan bercetak tebal pada Data (07).

(07) G : Ya, to fit with the rider body, if the riders are tall, it will be made higher but if the riders are short it will be lower ya, so you can adjust..bisa di-adjust or adjustable..is it right? What is the meaning of adjust? It can be apa tadi?

$S$ : To fits with the rider's body

$\mathrm{G}$ : To fits with the rider's body berarti itu bisa disesuaikan dengan tinggi atau rendahnya the riders.

$S$ : Tinggi atau pendeknya

$\mathrm{G}$ : Ya you are right tinggi atau pendeknya the rider's body. Adjustable berarti bisa di..?

(SL/P/1/XI/APRIL/2009)

Kedelapan, fungsi membuat inferensi. Peristiwa AK dari bIng ke dalam bI yang dilakukan oleh guru bahasa Inggris dalam pembelajaran bahasa Inggris di kelas digunakan untuk fungsi menyimpulkan penjelasan yang disampaikan dalam bahasa Inggris agar peserta didik memahami penjelasan atau informasi yang disampaikan. Fungsi tersebut ditunjukkan dalam tulisan bercetak tebal pada Data (08).

(08) G: But, remember, this is not a sentence yet. Ini bukan kalimat lho ya. Jangan salah tangkap. This is not a sentence, this is only a noun phrase. Ini noun phrase. Ini kalau dalam kalimat bisa berfungsi sebagai subyek atau objek. A beautiful girl sitting under the tree is..... Gadis cantik yang duduk di bawah pohon itu adalah... Jadi noun phrase yang panjang itu kan kadang yang membuat kita sulit memahami teks dalam bacaan, reading text itu karena noun phrase-nya panjang banget. Padahal intinya satu noun. Any question so far? You get the point of noun phrase? Intinya tahu ya. Dari satu kata dikembangkan menjadi noun phrase. Jadi inti katanya adalah kata benda itu sendiri, the noun itself. A group of words which functions as a noun. Kata bendanya.

S : Ya, bu.

G : In a sentence it can be a subject or object. Dalam satu kalimat, noun phrase bisa menjadi subyeknya atau objek.

(G/P/2/XI/MEI/2009)

Kesembilan, fungsi pengembangan kosakata. Dalam pembelajaran bahasa Inggris di kelas, sebagian guru bahasa Inggris menggunakan AK dari bIng ke dalam bI untuk pengembangan kosakata. Fungsi 
tersebut ditunjukkan dalam tulisan bercetak tebal pada Data (09).

(09) G: Okay. What is the synonym for battle?

$\mathrm{S}$ : fight

$\mathrm{G}$ : Ya.. fight. Kalau medan tempur bahasa Inggrisnya apa?

$S$ : Battle field.

G : Ya.. very good. Next brave. What is the noun of brave? Brave itu berani. Kalau keberanian?

S : Braveness..braven.. bravety...

$\mathrm{G}:$ No..no..no..

$S$ : Bravery.

G: Yes. Bravery. Ya.. bravery. Next, arrest. The synonym for the word arrest?

S : Catch.

(W/L/1/XI/MEI/2009)

Kesepuluh, fungsi membahas tugas atau pekerjaan peserta didik. Dalam pembelajaran bahasa Inggris di kelas, guru bahasa Inggris sering kali melakukan pembahasan latihan-latihan atau tugastugas yang telah dikerjakan peserta didik secara klasikal. Agar peserta didik dapat memahami latihan-latihan yang sedang dibahas, guru bahasa Inggris melakukan AK dari bIng ke dalam bI atau sebaliknya. Fungsi tersebut ditunjukkan dalam tulisan bercetak tebal pada Data (10).

(10) G : Have you finish?

$\mathrm{S}: \mathrm{No}$.

$\mathrm{G}$ : Number one Ilham please.

: Belum Mbak.

G : Ya ayo cepet dikerjain.

$S$ : Aku Mbak.

G : Okay. Yang lain silent please, ini temennya mau jawab. Let's we check the answer. Number one is Ilham. Ilham ayo.

S : Dewi Kadita realized that she... when she woke up that morning. $C$ turned to be a very ugly girl.

G: Ya Dewi Kadita realized that she turned to be a very ugly girl when she woke up that morning. Jadi Dewi Kadita realized. Realized? What is the meaning by realized?

$(\mathrm{E} / \mathrm{P} / 1 / \mathrm{X} / \mathrm{FEB} / 2012)$

Kesebelas, fungsi memberi feedback atau umpan balik. Dalam kegiatan pembelajaran bahasa Inggris, pemberian feedback atau umpan balik kepada peserta didik sangat diperlukan agar peserta didik mengetahui keberhasilan atau kesalahan yang telah dilakukan oleh peserta didik dalam mengerjakan tugas-tugas yang berikan oleh gurunya. Untuk melakukan pemberian feedback, guru bahasa Inggris melakukan AK dari bIng ke dalam bI agar semua peserta didik menangkap umpan balik yang diberikan oleh gurunya. Berikut diperikan contoh data untuk fungsi tersebut.

(11) G : Oh, no. Who knows? I have wait here for twenty minutes. What's wrong with the sentence? So, remember wait kalau ditambah -ed harus terbaca. Kamu baca seharusnya jangan wait saja. Temannya apa lagi, wanted, invited, repeated, good! Kamu baca seharusnya jangan wait saja. Do you still remember that? Iya to, kan mudah. I think you can express your anger in English! Apalagi agak galak kayak Rere! Nggak kok. Jadinya sekarang kalau mau marah in English sudah bisa ya. Now, the next exercise is on page 122. Arrange the dialogues. Do you understand the instructions? How many dialogues are there? (N/P/1/XI/APRIL/2009)

Keduabelas, fungsi melakukan refleksi. Dalam pembelajaran bahasa Inggris di kelas, guru bahasa dan peserta didik melakukan refleksi terhadap kegiatan pembelajaran bahasa Inggris. Agar peserta didik mudah menyampaikan refleksinya dan memahami refleksi yang disampaikan oleh guru bahasa Inggris dan peserta didik, AK dari bIng ke dalam bI dilakukam oleh guru bahasa Inggris. 
Fungsi melakukan refleksi tersebut ditunjukkan dalam tulisan bercetak tebal pada Data (12)

(12) G : Wilderness, their lives. Okay stop. Okay number two.Nilainya satu. Ya kan. Nilai ulangan vocabulary dapat satu. Ya kan. Berikutnya setelah Denta maharani ayo denta. Ayo, Maharini dulu, maharani dulu. Maharani. Ya okay. Sudah. S : Ya. Denta di diskualifikasi ya Denta.

G: Okay next time for your homework, your task karena mungkin Anda minggu depan itu libur ya. Anda belajar tentang apa itu tadi? Menceritakan tentang apa tadi circus ya. Okay see you next time.

(SA/L/1/X/APRIL/2009)

\section{Fungsi Pengelolaan kelas}

Fungsi pengelolaan kelas merujuk pada fungsi AK yang dimaksudkan untuk mengelola kelas. Fungsi ini dibedakan menjadi 13 fungsi, yakni (1) menarik perhatian siswa, (2) memberikan penugasan, (3) menandai pergantian topik, (4) meminta bantuan peserta didik, (5) mengatasi ketegangan, (6) menjaga kedisiplinan peserta didik, (7) memberikan motivasi kepada peserta didik, (8) memberikan apresiasi terhadap siswa, (9) memberikan peringatan kepada siswa, (10) memberikan giliran kepada siswa, (11) memarahi peserta didik dan (12) memelihara hubungan interpersonal. Berikut disampaikan beberapa contoh fungsi alih kode untuk pengelolaan kelas.

Pertama, menarik perhatian peserta didik. Alih kode dari bIng ke dalam bI atau sebaliknya digunakan untuk menarik perhatian siswa agar mereka berfokus pada materi pelajaran yang disampaikan. Berikut diperikan contoh data untuk fungsi tersebut sebagaimana disampaikan dalam tulisan bercetak tebal pada Data (13).

(13) G : Anyone has finished?

$S$ : Bentar pak saya baru nulis.
G : Apa tadi, general structure? General classification. Sudah?

S : (Siswa sibuk menyelesaikan tugasnya)

G : Okay, listen please e.... Bambang. Bambang will read you the outline. So

listen please. Tolong dengarkan ini, karena ini sebagai persiapan kita nanti e... presentasi. Baca dulu. Ini definisinya.

$S$ : (Salah seorang siswa membaca)

$\mathrm{G}$ : Sudah dengar?

$S$ : Gak.

G : Okay, yang keras. Repeat, please. (G/P/3/XI/MEI/2009)

Kedua, memberikan penugasan. Alih kode dari bIng ke dalam bI atau sebaliknya juga digunakan untuk fungsi pemberian arahan, latihan atau tugas kepada peserta didik. AK ini dilakukan agar peserta didik mengerti tugas atau kegiatan apa yang dilakukan oleh peserta didik dalam kegiatan proses belajar mengajar. Berikut contoh data untuk fungsi tersebut.

(14) G : Okay. The last exercise. There are jumbled paragraphs here. Disini ada paragraf yang acak. Rearrange please the jumbled paragraphs into two good texts, ke dalam dua teks. So, there are two texts here. Jadi disini ini ada dua teks. Plus, we are going to find out the title of the text. Judulnya teks ini apa saja. $Y a$, the use of seatbelt is mandatory, the first, the first text. And then, the second is six counselors to go on trial soon. Discuss with your friends. Berdiskusilah dengan teman-temanmu. And rearrange please the jumbled paragraphs here into two good texts. Ke dalam dua teks yang bagus susunannya.

$(\mathrm{K} / \mathrm{P} / 4 / \mathrm{X} / \mathrm{MEI} / 2009)$

Ketiga, menandai pergantian topik. AK dari bIng ke dalam bI atau sebaliknya dilakukan oleh guru bahasa Inggris untuk 
menandai pergantian topik. Dengan AK tersebut, peserta didik mengetahui topik yang dipelajari. Fungsi AK untuk penanda pergantian topik disampaikan dalam tulisan bercetak tebal pada Data (15).

(15) G: Okay. This is the score of your sumative test and and formative test. I would like to read siswa yang remedi. Waktu remedinya bersama. Next meeting ya. I don't say next week. Next meeting ya. Ya perhaps next Tuesday ya. Remedi ulangan hariannya.

$S$ : (Para siswa mendengarkan).

G : Okay students. The next topic is military. Sudah disiapkan. Military. Did you get the topic in the first semester? Ada gak di semester I. Topik ini. Gak ada ya?

(W/L/1/XII/APRIL/2009)

Keempat, fungsi meminta bantuan peserta didik. Peristiwa AK dari bIng ke dalam bI atau sebaliknya dilakukan oleh guru bahasa Inggris untuk meminta bantuan kepada peserta didik, misalnya mengambilkan buku pelajaran, menghapuskan papan tulis, membuka atau menutup pintu, dan sebagainya. Tulisan bercetak tebal pada Data (16) menunjukkan fungsi AK untuk meminta bantuan peserta didik.

(16) G : Okay, students good morning.

$S$ : Good morning.

$\mathrm{G}$ : Is there any student absent today?

$S$ : Nuraini

G : Okay, I want three students to go to the library to borrow dictionaries. Okay, chairman. Depannya itu siapa itu, ya both of you sana, you borrow dictionaries overthere. 14 dictionaries. Yang absent tadi siapa?

$S$ : Nuraini Brilian.

$\mathrm{G}$ : Okay, Brilian is sick. And then, only one?

$S:$ Yes.

(W/L/1/XII/APRIL/2009)
Kelima, fungsi mengatasi ketegangan. Penggunaan bahasa Inggris secara terus menerus yang dilakukan oleh guru bahasa Inggris dalam komunikasi di kelas menyebabkan ketegangan bagi sebagian peserta didik yang memiliki kemampuan bahasa Inggris yang belum memadai. Untuk mengurangi ketegangan tersebut, guru bahasa Inggris melakukan AK dari bIng ke dalam bI. Tulisan bercetak tebal pada Data (17) menunjukkan fungsi AK untuk mengatasi ketegangan.

(17) G : And then, next. The old man slipped. He got off the bus. The old man slipped. He got off the bus. How do you combine it? How do you combine them, Fatoni? Getting off the bus, the old man slipped. What is the meaning of slipped? Oo..terpeleset. Good! Thank you! Jadi, while he was getting off the bus, the old man slipped. Right! Good! Jadi ketika dia turun dari bis, dia kepeleset. So, you must understand always that, you must imagine what happen at that time.

Jadi, kamu bisa ngerti beneran, jangan kebalik. Ketika kepeleset, dia? Oo.,.nanti kuwalik-walik! Ada anak saya yang kuwalik kemarin. Ketika dia keslomot, Ketika dia sedang keslomot dia memasak. Gimana pula. Ya, thank you! That is first, and then second.

$\mathrm{S}$ : (Semua siswa ketawa)

(N/P/1/XI/APRIL/2009)

Keenam, memberikan motivasi kepada peserta didik. Peristiwa AK dari bIng ke dalam bI atau sebaliknya dilakukan untuk memberikan motivasi kepada peserta didik agar mereka memiliki motivasi untuk mempelajari materi bIng secara sungguh-sungguh. Lihat tulisan bercetak tebal pada Data (18).

(18) G : Hi, good morning.

$\mathrm{S}$ : Morning, Ma'am.

$\mathrm{G}$ : I will give you the result of the English test after the class. Nanti ya, nanti 
akan saya bagikan hasilnya. Tapi keseluruhan buruk!

S : Yah...

G : So, you must study hard from now on! Kalian harus kerja keras mulai dari sekarang. You have only three months. Kita hanya punya waktu 3 bulan lagi. Okay, have you read a newspaper today? What do you know about Situ Gintung? What do you know about Situ Gintung? What happened there?

(K/P/2/XI/APRIL/2009)

Ketujuh, fungsi memberikan apresiasi terhadap peserta didik. Untuk menghargai prestasi peserta didik atau keberhasilan dalam melakukan tugas-tugas yang diberikan, guru bahasa Inggris seringkali melakukan AK dari bIng ke dalam bI. Dengan dilakukannya AK dari bIng ke dalam bI, peserta didik merasa lebih bangga dengan apa yang telah dicapainya karena pesan yang disampaikan oleh guru bahasa Inggris dimengerti oleh seluruh peserta didik di dalam kelas. Lihat Data (19).

(19) G : What did Dandy feel at that time? Dandy felt annoyed. What do you say in Bahasa Indonesia? Feel annoyed, what is it? Come on, what is it? What do you say in Bahasa Indonesia? Merasa Kesal. Okay, merasa kesal. Kalau kamu tidak bicara keras ini telinganya. Thank you! Merasa kesal. What else? Oo...sebel kata Alfian. Merasa kesal. Merasa sebel. Kamu tadi memperagakan dengan bagus. Okay, thank you, Tomo! Thank you.

(N/P/3/XI/APRIL/2009)

Kedelapan, memberikan peringatan atau nasehat kepada peserta didik. Dalam proses pembelajaran bahasa Inggris, seringkali ditemukan beberapa peserta didik datang terlambat, membuat kegaduhan, membuat ulah agar mereka diperhatikan, atau tidak mau mengerjakan tugas yang diberikan oleh gurunya, membuat kesalahan, dan sebagainya. Untuk mengatasi permasalahan tersebut, guru bahasa Inggris melakukan AK dari bIng ke bI. Fungsi AK untuk pemberian peringatan kepada peserta didik disampaikan dalam tulisan bercetak tebal berikut.

(20) G : Ya.. catch, menangkap. Next the other word crew. What is the synonym of crew? Is it the team the same meaning with crew? Ya. it is different. Next.. personnel. Double n. Next duty. Bagaimana membacanya, mbak?

$S$ : duty.

$\mathrm{G}$ : Jangan ada yang keliru ya membacanya. Nanti pas exercise duty apa? Apa ini? What is the meaning of this word? Ya.. thing that you should do ya, what you should do. Ada military duty. Kata apa itu? Maknanya apa? Military duty.

(W/L/1/XII/APRIL/2009)

Kesembilan, memberikan giliran kepada peserta didik. Dalam memberikan giliran untuk menjawab pertanyaan atau melakukan tugas-tugas lain, guru bahasa Inggris melakukan AK dari bIng ke dalam bI atau sebaliknya. Fungsi AK untuk pemberian giliran kepada peserta didik disampaikan dalam tulisan bercetak tebal pada Data (21).

(21) G : Okay. Now, we go on to something here. The direction is, read the conversation, read the conversation and pay attention to the italic parts. Okay. Coba Anita dengan teman sebelahnya. Yang lain menyimak ya.

$S$ : (Dua siswi membaca dialog)

$\mathrm{G}$ : Okay, once again.

$\mathrm{S}$ : (Dua siswi membaca dialog)

G: Okay. Can you hear that? Siapa, siapa yang di pojok belakang? Rangga? Rangga, can you hearher? $\mathrm{S}:$ No.

(IS/P/1/XI/MEI/2009) 
Kesepuluh, memarahi peserta didik. Dalam pembelajaran bahasa Inggris, seringkali peserta didik membuat marah atau jengkel kepada guru bahasa Inggris. Agar pesan kemarahan atau kejengkelannya tersampaikan kepada peserta didik, guru bahasa Inggris cenderung melakukan AK dari bIng ke dalam bI. Lihat contoh berikut.

(22) G : (Berbicara ke semua siswa) Ini tadi kenapa ya kamu? Masuk sekolah ini tadi kenapa? Hari kejepit means that you do not need to pay attention? No! Atau apa tho? Ini kok situasi kelas sama sekali nggak kondusif ini kenapa to?

$S$ : Tired.

G : Oo...you are tired? Why? Kok ada yang berbeda sekali? Kenapa ini? Apa gara-gara ada berita dari Tomo kalau pulang pagi? Pulang pagi atau tidak, pulang siang atau tidak, would you please try to concentrate on your study? Kok rodo ada kesan memeng, ada kesan pengen ngobrol dua hari nggak ketemu. Ndak ini blas kamu. Kok seperti ini ya? Okay, come on! Let's study!

(N/P/3/XI/APRIL/2009)

Kesebelas, fungsi menyindir peserta didik. Peristiwa AK dari bIng ke dalam bI atau sebaliknya dalam komunikasi di kelas dimaksudkan untuk menyindir peserta didik yang tidak memperhatikan penjelasan yang disampaikan. Berikut contoh data terkait dengan fungsi tersebut.

(23) G : Is it right? Betul? Salah? Wrong-nya dimana? Spent? Harusnya?

$S$ : Pakai $-d$.

G : Pakai - $d$ kan Verb 1. Ini indirect lho! Has? Has spent? Is it right? Bener opo salah? Betul po salah? Betul? Lah tadi kamu guyon sendiri nggak mau nyocokin dengan catetannya. Betul po salah? Aku manut! Kalau Anda bilang betul yo wes tak anggep bener, kalau tok bilang salah, yang mana yang salah. Betul po salah? Mung menentukan betul po salah gampang kok! Betul po salah?

$S$ : Betul.

(B/P/5/X/APRIL/2009)

Keduabelas, memelihara hubungan inpersonal. Peristiwa AK dari bIng ke dalam bI dalam pembelajaran bahasa Inggris di kelas digunakan untuk memelihara hubungan interpersonal antara guru dan peserta didik. Berikut disampaikan contoh data untuk fungsi tersebut.

(24)G: Okay, Mas Nanda, is it clear enough for you? Let's try to study this. Going to Indonesia will be an exciting experience for Marry.

(N/P/1/XI/APRIL/2009)

(25) G : Crime is a serious problem in a big city. Do you agree or not, Mbak Rizki? Crime is a serious problem.

S : Yes.

(S/P/3/XI/APRIL/2009)

\section{Fungsi Penanda Tutur}

Yang dimaksud dengan fungsi penanda tutur adalah fungsi AK yang menandai tuturan pengalih kode. Penanda tutur ini terdiri atas berbagai bentuk tuturan seperti bentuk well, okay, ya, dan sebagainya. Berikut disampaikan contoh data untuk masing-masing penanda wacana.

(26) G : The other source, ya nanti kita lihat, ada yang lain?

$S$ : Keadaan disana setelah gempa.

G: Mungkin, bisa juga. Well, lets we check your prediction. Kita cek prediksi kalian.

(AA/P/1/X/MARET/2012)

(27) G : Ya the second type tipe yang kedua. Yang tidak faham langsung menyesuaikan kenapa kok bisa yang 
type two. Okay yang number 11 itu tipe keberapa?

$S$ : Ketiga.

G : Okay nomer 13. Tipe ke berapa nomer 13?

$S$ : Dua.

G: Tipe ketiga, berikutnya.14 tipe keberapa?

(SA/L/3/X/APRIL/2009)

\section{SIMPULAN}

Peristiwa AK dari bIng ke dalam bI atau sebaliknya yang dilakukan oleh para guru bahasa Inggris dalam pembelajaran bahasa Inggris di kelas memiliki berbagai fungsi yang dikategori menjadi tiga, yakni (1) fungsi penyampaian materi, (2) fungsi pengelolan kelas, dan (3) fungsi pemarkah wacana. Fungsi penyampaian materi dipilah menjadi 12 fungsi. Fungsi-fungsi tersebut mencakup (1) fungsi klarifikasi atau konfirmasi, (2) fungsi reiterasi, (3) fungsi eksplanasi, (4) fungsi ekplorasi, (5) fungsi elaborasi, (6) fungsi pengecekan pemahaman, (7) fungsi penekanan terhadap unsur-unsur kebahasaan tertentu, (8) fungsi membuat inferensi, (9) mengembangan kosakata, (10) membahas tugas atau pekerjaan peserta didik, (11) memberi feedback atau umpan balik, dan (12) melakukan refleksi. Fungsi pengelolaan kelas dibedakan menjadi 12 fungsi, yakni fungsi pengelolaan kelas ini terdiri dari berbagai fungsi, yakni (1) menarik perhatian siswa, (2) memberikan arahan, (3) menandai pergantian topik, (4) meminta bantuan peserta didik, (5) mengatasi ketegangan, (6) menjaga kedisiplinan peserta didik, (7) memberikan motivasi kepada peserta didik, (8) memberikan apresiasi terhadap siswa, (9) memberikan peringatan kepada siswa, (10) memberikan giliran kepada siswa, (11) memarahi peserta didik, dan (12) memelihara hubungan interpersonal.

Penemuan tersebut di atas mengimplikasikan bahwa peristiwa AK dari bIng ke dalam bI atau sebaliknya dalam pembelajaran bahasa Inggris di kelas tidak perlu diperdebatkan karena AK tersebut tidak dilakukan secara serampangan oleh para guru bahasa Inggris di SMA di DIY. Dengan kata lain, pengalihkodean dari bIng ke dalam bI dalam pembelajaran bahasa Inggris di kelas perlu disebarluaskan kepada para guru bahasa Inggris selama pengalihkodean tersebut dilandasi oleh fungsi-fungsi tersebut di atas. Seiring dengan perkembangan kemampuan bahasa Inggris yang dimiliki oleh peserta didik dan guru bahasa Inggris, AK dari bIng ke dalam bI atau sebaliknya dapat diminimalisasi agar pemerolehan bahasa target dapat dilakukan secara maksimal.

\section{UCAPAN TERIMA KASIH}

Pada kesempatan ini penulis mengucapkan banyak terima kasih kepada Prof. Dr. Soepomo Poedjosoedarmo sebagai promotor dan Prof. Dr. Stephanus Djawanai, M.A. sebagai ko-promotor, yang telah memberikan bimbingan dan arahan dalam penulisan disertasi yang berjudul "Alih Kode dalam Ranah Pendidikan" yang menjadi induk tulisan ini. Ucapan terima kasih juga disampaikan kepada para reviewer Prof. Dr. Zamzani, M.Pd. dan Sugirin, M.A., Ph.D. yang telah memberi catatan, masukan, dan pembenahan aspek kebahasaan untuk perbaikan artikel ini.

\section{DAFTAR PUSTAKA}

Ajmal, M.G. 2010. Code-switching: Awareneness about its Utility in Bilingual Classroom. Bullettin of Education and Research.Vol.32, No. 2 pp.23-44.

Auer, J.C.P. 1984. Bilingual conversation. Amsterdam: John Benjamins B.V.

Butler, Y. G., \& Gutierrez, M. B. (2003). "Learning climates: A case of 4th grade students in an English-only district in California". Bilingual Research Journal, 27 (2), 207-224.

Cook, V. 1989. “Reciprocal Language Teaching: Another Alternative". Modern English Teacher, 16 (3\4), 48-53. 
Cook, V. 1991. Second Language Learning and Language Teaching. Melbourne: Edward Arnold/ Hodder Headline Group.

David, M.K. 2003. "Role and functions of code-switching in Malaysian courtrooms". Multilingua, 22, 5-20.

Fantini, A. 1985. Language acquisition of a bilingual child. A Sociolinguistic Perspective. San Diego: College Hill Press.

Faltis, C.J. 1996. "Learning to Teach Content Bilingually in A Middle School Bilingual Classroom". Bilingual Research Journal, 20 (1), 29-44.

Goyvaerts, L.G. \& Z.T. Zembele. 1992. "Code-switching in Bukavu". Multilingual and Multicultural Development, 13: N 1-3.

Gumperz J.J. 1976. The social significance of conversational code-switching. $\mathrm{Pa}$ pers on Language and Context 1-46. San Diego: University of California.

Kamwangamalu, N.M. 1992. "Mixers and mixing,English Across cultures". World Englishes, 11 (2/3), 173- 181.
MacSwan, J. 1999. A Minimalist Approach to Intra-sentential Code Switching. New York: Garland Publishing.

McClure, E. 1981. Formal and functional aspects of the code-switched discourse of bilingual children. In R.P. Durán (Ed.), Latino Language and Communicative Behaviour (pp. 133-152). Norwood, NJ: Ablex.

Poedjosoedarmo, Soepomo. 1975. Kode dan alih kode. Dalam Widyapurwa 15. Yogyakarta: Balai Penelitian Bahasa.

Reyes, I. 2004. Functions of code-switching in schoolchildren's conversation. Bilingual Research Journal, 28 (1), 77-98.

Romaine, S. 1995. Bilingualism. Oxford UK: Basil Blackwell Ltd.

Wardhaugh, R. 2010. An Introduction to Sociolinguistics.Massachusetts: Blackwell Publishers.

Zentella, A. C. 1997. Growing up bilingual. Maiden, MA: Blackwell. 